\title{
BIOSYNTHESIS OF THE INDOLE AND COLCHICUM ALKALOIDS
}

\author{
A. R. BAtTersby
}

The Robert Robinson Laboratories, University of Liverpool, Liverpool, U.K.

There has been enormous progress over the past fifteen years or so in our understanding of the ways in which complex natural products are synthesized in living systems. In the field of alkaloids, as elsewhere, research during the initial phase ${ }^{1}$ pin-pointed those substances which are used as the common building blocks, examples being acetic acid, ornithine and lysine for the reduced systems, and tyrosine, phenylalanine, 3,4-dihydroxyphenylpyruvic acid, and tryptophan for the many bases containing aromatic nuclei. Such knowledge allows the second phase of research to be undertaken; here the intermediates on the pathway are identified and this in turn leads to a study of the mechanism of each step in the biosynthetic sequence. At present a most exciting stage has been reached where hypothesis ${ }^{2-7}$, tracer experiment $t^{8,9}$, structure determination, and isolation work can be combined in a very powerful way. We can illustrate all these aspects by examining two quite different groups of alkaloids which have held our deep interest for several years. One is the large family of indole alkaloids, exemplified by corynantheine (I), strychnine (II), catharanthine (IV, Figure 1), and vindoline (VII), and the other contains the alkaloids found in Colchicum species of which the ancient poison colchicine (XXXVI) is the best known member. The origins of these groups of alkaloids have remained until very recently the two major unsolved problems in the field.

The number of known indole alkaloids has increased sharply over the last few years and there are now about six hundred ${ }^{10,11}$. A tryptamine
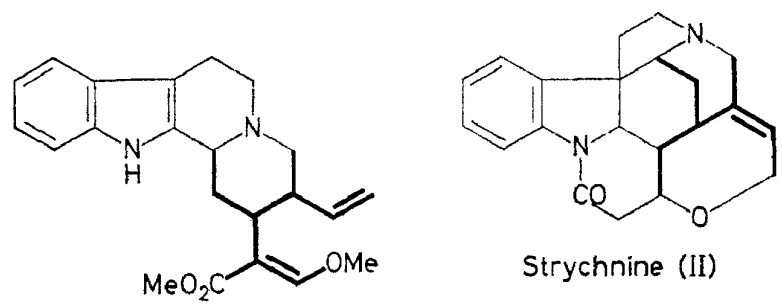

Strychnine (II)

Corynantheine (I)

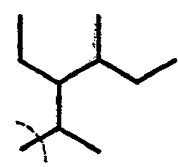

(III)
$\mathrm{C}_{9-10}$ Unit

Corynantheine-Strychnine type 
A. R. BATTERSBY

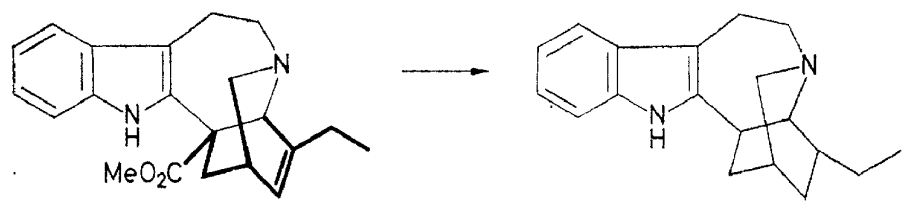

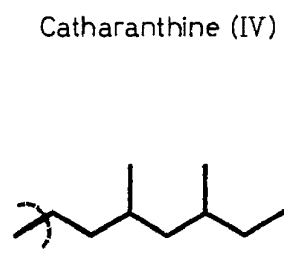

(VI)

$\mathrm{C}_{9-10}$ Unit; Iboga type
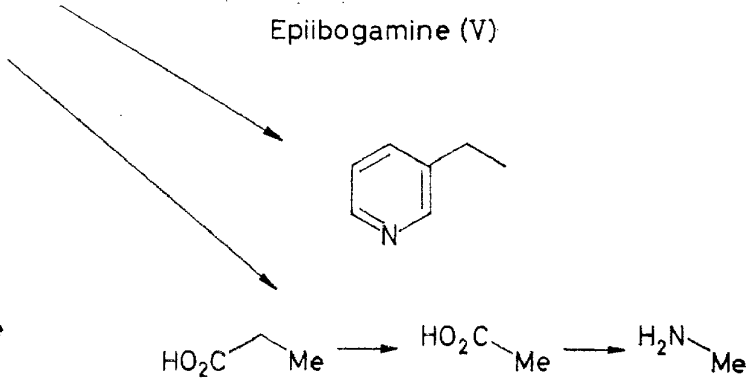

Figure 1

residue (normal bonds in I, IV, and VII) appears almost invariably and in the few cases examined by tracer methods ${ }^{12}$, this residue has been found to be derived in the expected way from tryptophan. The remaining nine or ten skeletal carbon atoms (thickened bonds in I, IV, and VII) appear in what at first sight seems a bewildering variety of different arrangements but closer inspection allows three main groups to be discerned ${ }^{13}$. Together, these three main groups account for the vast majority of indole alkaloids. We can conveniently refer to them as: $(a)$ the corynantheine-strychnine

(A)<smiles>[H][R2]1ccc(CC(N)C(=O)O)cc1</smiles>

(B)<smiles>O=C(O)C1(C(=O)O)C=CC(O)C=C1</smiles>

(C)

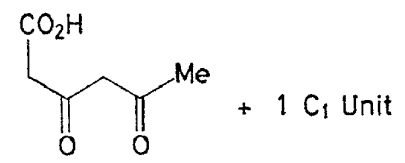<smiles>O=C(O)CC(=O)O</smiles>

Figure 2 


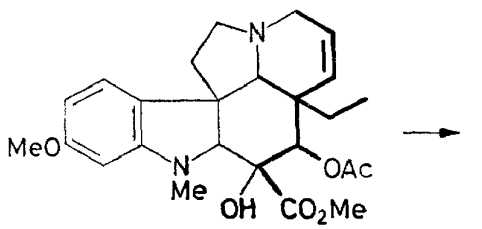

Vindoline (VII)

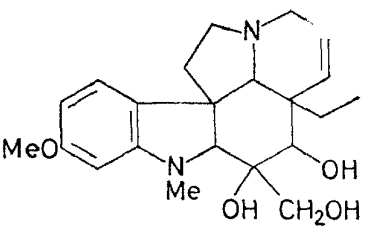

(VIII)

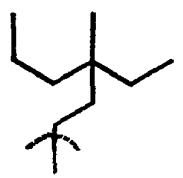

(IX)
$\mathrm{C}_{9-10}$ Unit

Aspidosperma type

type which possess the $\mathrm{C}_{9-10}$ unit (III), (b) the Aspidosperma type having the $\mathrm{C}_{9-10}$ unit (IX), and (c) the Iboga type where the $\mathrm{C}_{9-10}$ unit appears as (VI). In those alkaloids where only nine skeletal carbons appear in addition to the tryptamine residue, it is invariably the carbon atom indicated by the dotted line which has been lost.

Our own experimental study of the origin of this ubiquitous $\mathrm{C}_{\mathbf{9}-10}$ unit started some six years ago and all the early work was designed to test rigorously three hypotheses,14,15; these are illustrated in Figure 2 simply by the units involved. Our results have been published ${ }^{16-18}$ together with complementary work ${ }^{19-21}$ and it is only necessary therefore to summarize the main findings. It was proved beyond doubt that all three hypotheses are incorrect; the earlier experimental support ${ }^{15,22}$ for the hypothesis $(C)$ [in Figure 2] has since been withdrawn ${ }^{23}$. Further, the results established that a $\mathrm{C}_{1}$-unit is not involved in the biosynthesis. The only hypothesis in accordance with this finding is that due to Thomas $^{24}$ and Wenkert ${ }^{7}$, which suggested a relationship of the $\mathrm{C}_{9-10}$ unit to the cyclopentane monoterpene skeleton (XII). Figure 3 shows how the corynantheine-strychnine $\mathrm{C}_{9-10}$ unit (III) could be derived by cleavage of the cyclopentane ring of some unknown monoterpene illustrated here simply as a skeleton without any indication of its oxidation level. One can extend the structural relationships by observing that the $\mathrm{C}_{9-10}$ units of the Aspidosperma and Iboga types may be derived by a combination of a further bond fission as indicated and a bond formation in the direction either $(a)$ or $(b)$. It must be emphasized that Figure 3 is not intended to convey any information about the timing of the various changes. This scheme simply means that the three types of $\mathrm{C}_{9-10}$ units may be so related by steps occurring at points, as yet unknown, somewhere along the biosynthetic pathway.

A test of the monoterpene theory clearly involves feeding experiments with sodium mevalonate $(\mathrm{X})$ and our first small incorporations of this precursor were achieved into the alkaloids of Cephaelis ipecacuanhat and

†This plant contains the isoquinoline relatives of the indole alkaloids 
A. R. BATTERSBY

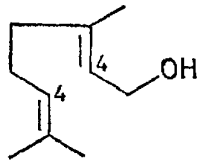

(XI)

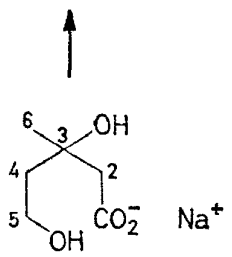

$(X)$

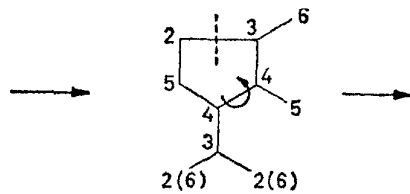

(XII)
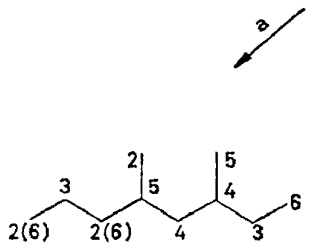

(VI)

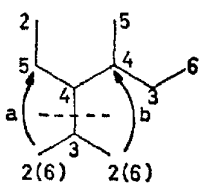

(III)
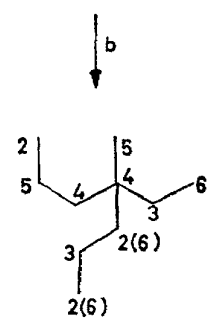

(IX)

Figure 3

Rauwolfia serpentina ${ }^{18}$. Other plants, particularly Rhazia stricta and Vinca rosea were better able to draw external supplies of sodium mevalonate into their biosynthetic systems and gave satisfactory incorporations of activity ${ }^{25}$. Thus, sodium $\left[2-{ }^{14} \mathrm{C}\right]$ mevalonate fed to $R$. stricta yielded radioactive 1,2dehydroaspidospermidine (XVII; 0.15 per cent incorporation) and similarly, active vindoline (VII; 0.5 per cent incorporation) was isolated from $V$. rosea plants. The latter plant also afforded radioactive serpentine (XIII), ajmalicine (XV), catharanthine (IV) and perivine (XIX). Simultaneously and quite independently, Professors A. I. Scott and D. Arigoni and their respective coworkers carried out parallel experiments ${ }^{26,27}$. All the results which follow were obtained in our Robert Robinson Laboratory and our colleagues' work will be drawn in at the appropriate points by indicating on the various Figures which results they also have obtained; this will be done by $\mathrm{A}^{27}$ and $\mathrm{S}^{26}$ (for Arigoni and Scott respectively), the superscripts being literature references.

In our own experiments, it was decided to determine the labelling pattern generated in each of the three types of alkaloid by feeding the plants with various sodium mevalonates carrying specific ${ }^{14} \mathrm{C}$-labels. $\left[2-{ }^{14} \mathrm{C}\right] \mathrm{Mevalono}-$ lactone is available commercially and specimens of $\left[3-{ }^{14} \mathrm{C}\right]-,\left[4^{-14} \mathrm{C}\right]-$, and $\left[5-{ }^{14} \mathrm{C}\right]$ mevalonolactone were synthesized ${ }^{28,29}$; these were utilized in separate feeding experiments with Rhazia stricta and Vinca rosea plants. A further essential requirement was the development of unambiguous methods for degrading the labelled alkaloids and the procedures used are shown in Figures 1 and 4-7. In the design of the various sequences, we drew upon previous work, particularly the base cleavage of serpentine (XIII) to afford harman ${ }^{12}$ (XIV) (Figure 4) the hydrolysis and decarboxylation of 
<smiles>CC(=O)C1=COC(C)C2C[n+]3ccc4c([nH]c5ccccc54)c3CC12</smiles>

Serpentine (XIII)<smiles>CNN</smiles>

$$
\begin{aligned}
& \mathrm{CO}_{2} \mathrm{H} \\
& \stackrel{\mathrm{Me}}{\mathrm{Me}}
\end{aligned}
$$<smiles>Cc1nccc2c1[nH]c1ccccc12</smiles>

(XIV)<smiles>CC1CCC(Nc2ccccc2I)=C1N</smiles>

Figure 4

ajmalicine $(\mathrm{XV})$ followed by Wolff-Kishner reduction of the product to yield ajmaliciol ${ }^{7}$ (XVI) (Figure 5), and the conversion of catharanthine (IV) by hydrogenation and hydrolysis into epiibogamine ${ }^{30}$ (V) (Figure 1). The subsequent steps, especially the Kuhn-Roth and Schmidt degradations (which were also used to examine the ethyl side-chain of vindoline) were rigorously controlled by the use of standard substances at a known level of radioactivity. Finally, it was necessary to devise a suitable method for the isolation of the carbon atom marked 2 in 1,2-dehydroaspidospermidine (XVII) (Figure 6). Reduction of the alkaloid with lithium aluminium hydride $^{31}$ and protection of the indolinic $>\mathrm{NH}$ by acetylation allowed Emde and Hofmann degradations to be carried out as for aspidospermine ${ }^{32}$. Cleavage of the olefin with osmium tetroxide-periodate then afforded the required carbon as formaldehyde. The degradation of perivine is shown in Figure 7.

These then are the methods used to degrade the various alkaloids isolated from each feeding experiment and the results are collected in Figure 8. This illustrates the patterns expected on the basis of head-to-tail combination of two $\mathrm{C}_{5}$ units (derived from mevalonate) to yield a cyclopentane system

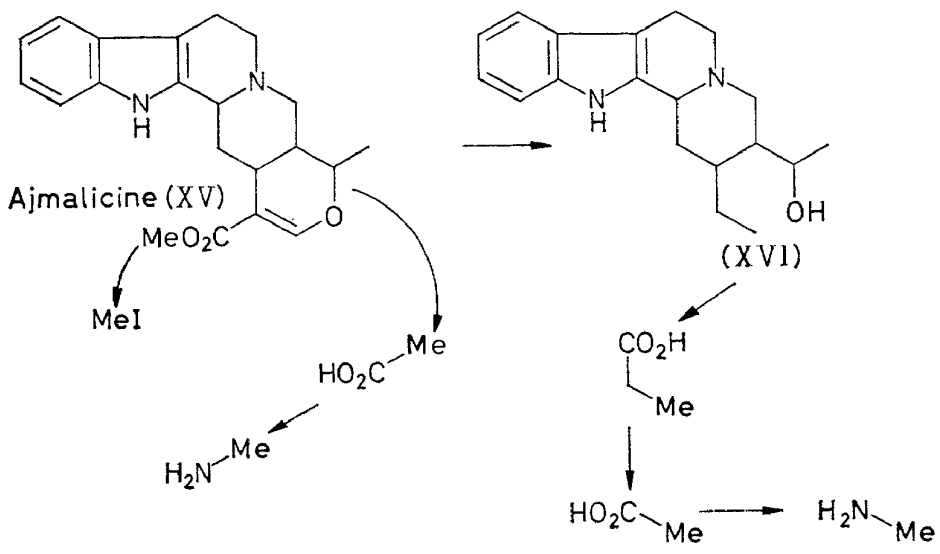

Figure 5 
<smiles></smiles>

1,2-Dehydroaspidospermidine (XVII)<smiles>CCC(C)(C)C(=O)O</smiles><smiles>CCC12CCCN(C)CCC(CC)(C1)C1c3ccccc3N(C)CCC12</smiles><smiles>CCC1(CC)CCC(Nc2ccccc2CCC(C)(C)C)C(CC)(CC(C)(C)C)C1</smiles>

(XVIII)

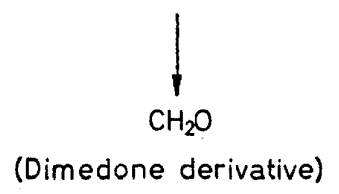

Figure 6

and subsequent cleavage of it. The underlined numbers (in Figure 8 ) indicate the positions which have been proved to be so labelled from the appropriately labelled sodium mevalonate. The quantitative results agreed closely with the theoretical values. These results lead to several important conclusions and we shall concentrate initially on the corynantheinestrychnine type of $\mathrm{C}_{\mathbf{9}-\mathbf{1 0}}$ unit. The results prove that a bond has been formed during the biosynthesis between the $\mathrm{C}-4$ carbons of the two mevalonate residues in agreement with cyclopentane ring-closure. Further, a labelling pattern which is almost complete has been derived for the corynantheinestrychnine unit and the pattern is quantitatively in agreement with the illustrated scheme; one should notice that $\mathrm{C}-2$ and $\mathrm{C}-6$ of one mevalonate<smiles>CC=C1CNC(Cc2c(Cl)[nH]c3ccccc23)CCC1C(C)=O</smiles>

Perivine $(X \mid X)$
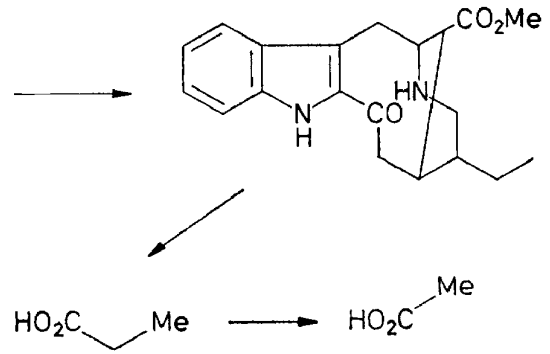

Figure 7 


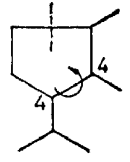

$\left(2 \times 10^{19}\right)$

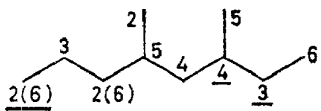

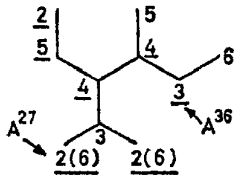

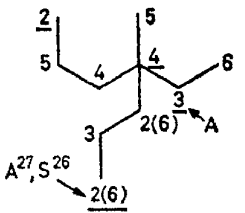

Figure 8

unit became equivalent during the biosynthesis as was found earlier for the cyclopentane monoterpene plumeride ${ }^{33}$. Finally, the labelling patterns derived so far for the Iboga and Aspidosperma types of $\mathrm{C}_{\mathbf{9 - 1 0}}$ unit are in complete agreement with their suggested derivation at some stage from the corynantheine-strychnine unit in ways we have already considered.

These results taken as a whole constitute powerful evidence supporting the formation of a cyclopentane monoterpene skeleton during the biosynthesis of indole alkaloids but it was important to obtain further evidence that a head-to-tail $\mathrm{C}_{10}$ unit is involved. Bearing in mind present knowledge of the biochemical transformation of mevalonic acid, one would expect geraniol (XI), or a derivative thereof, to act as a precursor of the cyclopentane system. Accordingly, [2-14 G]geraniol was prepared by known methods ${ }^{34}$ and was converted largely into the corresponding pyrophosphate. This was incorporated into all three types of indole alkaloids in Vinca rosea plants, the yield being four to thirty times higher than had been obtained

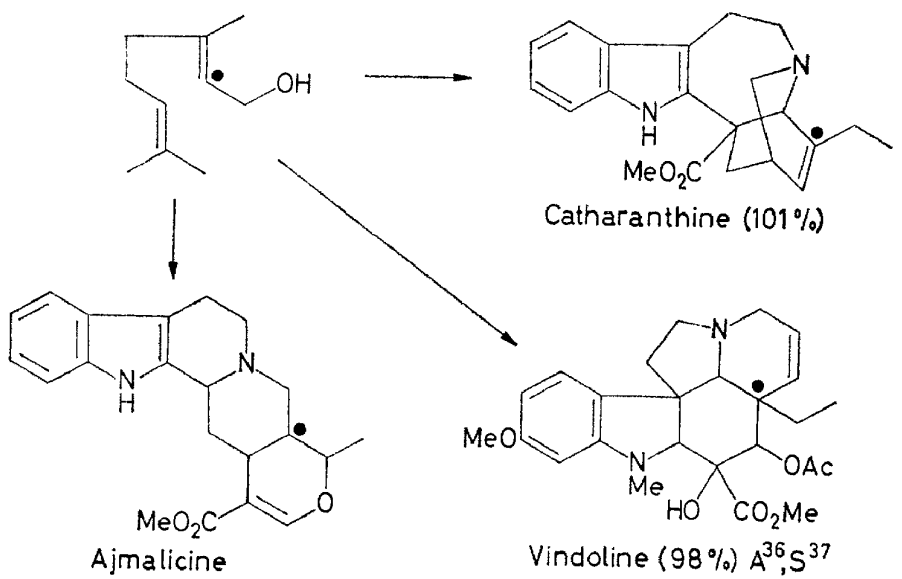

Figure 9 


\section{A. R. BATTERSBY}

from sodium mevalonate. The label of geraniol had been selected to allow ready isolation of the radioactive carbons from the various alkaloids (see Figure 9). Thus, for vindoline (as its desacetyl derivative) and catharanthine, Kuhn-Roth degradation afforded propionic acid of the same molar activity as the original alkaloid (see percentages in Figure 9) together with acetic acid which was radio-inactive. All the activity of these alkaloids is therefore located at the indicated positions ${ }^{35}$, both results being entirely consistent with the cyclopentane monoterpene scheme (Figure 3). Work is still in progress on ajmalicine and the present position is that six of the ten carbon atoms of the $\mathrm{C}_{10}$ unit have been shown to carry no activity, so limiting the label to $\mathrm{C}-3,14,20$ and 21 ; the expected site of labelling is $\mathrm{C}-20$.

We can now attempt with some confidence to discover the nature of the cyclopentane monoterpenes (for it is probable that there are several) which lie on the biosynthetic pathway to the indole alkaloids. If one considers the various possible oxidation levels of the ten carbon atoms of a cyclopentane monoterpene skeleton it turns out that there are $2 \times 10^{19}$ possible structures. We were greatly helped in reducing this number by the structural work on ipecoside which we have been carrying out in collaboration with Professors Janot and Levisalles. This substance is a glucoside occurring in Ipecacuanha plants which also biosynthesize the isoquinoline analogues of the indole alkaloids. Thus, the Ipecacuanha alkaloid

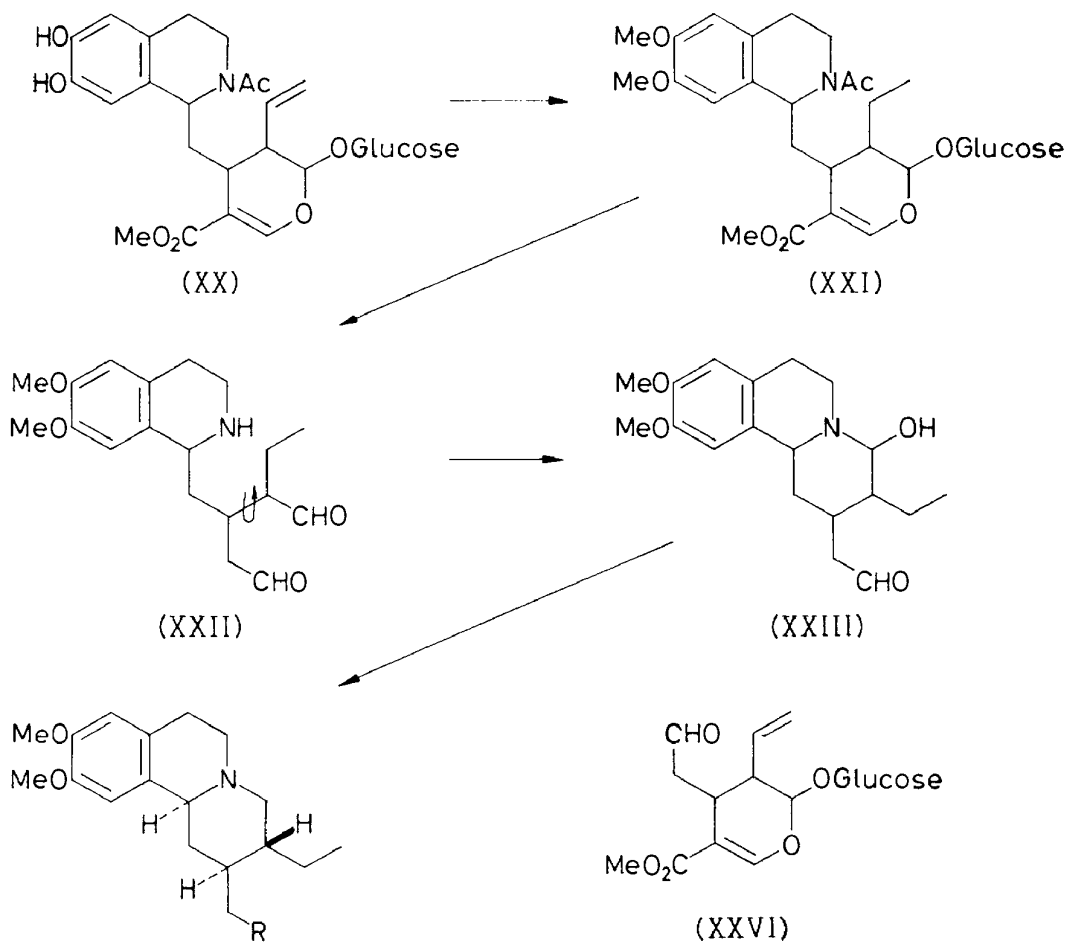

Protoemetine (XXIV); $\mathrm{R}=\mathrm{CHO}$

Dinydroprotoemetine $(\mathrm{XXV}) ; \mathrm{R}=\mathrm{CH}_{2} \mathrm{OH}$ 


\section{BIOSYNTHESIS OF THE INDOLE AND COLCHICUM ALKALOIDS}

protoemetine $^{38}$ (XXIV) should be compared with corynantheine (I). It is not possible here to cover the extensive chemical and spectroscopic work which led us to consider the constitution (XX) for ipecoside; it will suffice to say that this structure accommodates all the experimental findings. To establish this constitution beyond doubt and at the same time to determine the complete absolute stereochemistry, we decided to correlate ipecoside with protoemetine (XXIV). Acidic hydrolysis cleaved the $N$-acetyl group and the ester function to allow decarboxylation of the $\beta$-aldehydo acid. The mixture of bases so obtained was expected to contain the carbinolamine (XXIII) which should be susceptible to reduction by dissolving metals.<smiles>C=CC1C(O)OC=C(C(C)=O)C1CC=O</smiles><smiles>[R]C1OC=C(C(C)=O)C2CC(O)CC(CO)C1C2O</smiles><smiles>CCC1C(C(=O)OC)=COC(O)C1C(C)O</smiles>

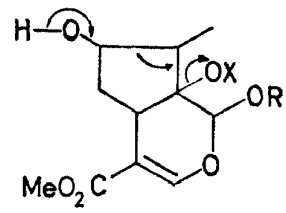<smiles>CC=C1C(O)OC=C(C([O+])O)C1CC=O</smiles>

Figure 10

Zinc-sulphuric acid reduction afforded a mixture from which dihydroprotoemetine $(\mathrm{XXV})$ was isolated. The constitution $(\mathrm{XX})$ is therefore established in every detail and ipecoside stands as the first example of a mixed isoquinoline--monoterpene alkaloid.

We can now speculate that the related base $(\mathrm{XX},>\mathrm{NH}$ in place of $>\mathrm{NAc}$ ) is the biosynthetic precursor of protoemetine and that ipecoside arises by a nitrogen-blocking acetylation. If this is true, the substance which combines with dopamine to afford desacetylipecoside could reasonably be the aldehyde (XXVI) or its equivalent; we are now close to a cyclopentane monoterpene. How might such an aldehyde (XXVI) be generated by suitable fragmentation of the cyclopentane ring? Figure 10 sets out some reasonable possibilities where $\mathrm{X}$ might be a phosphate residue to provide a good leaving group. These hypothetical precursors can be 


\section{A. R. BATTERSBY}

compared with the four natural monoterpenes which they most nearly resemble, verbenalin ${ }^{39}$ (XXVII), genepin ${ }^{40}$ (XXIX), monotropeine ${ }^{41}$ shown as the methyl ester (XXX), and $\operatorname{loganin}^{42}$ (XXXI). The last was $a$ priori the most attractive in that it is structually closest to the hypothetical precursors and, moreover, occurs alongside indole alkaloids in Strychnos species $^{42}$. All four compounds (XXVII), (XXIX), (XXX) and (XXXI)<smiles>[X]C1=CC(C)C2(C1)C(OC)OC=CC2C(C)=O</smiles>

Verbenalin (XXVII); $X=0$

Dihydroverbenalin $(X X V I I) ; X=H, O H$<smiles>COC1OC=C(C(C)=O)C2C=CC(O)(CO)C12CO</smiles>

Monotropeine ester (XXX)<smiles>CC(=O)OC(C)=O</smiles><smiles>COC1OC=C(C(C)=O)C2CC(O)C(C)C12</smiles>

Loganin (XXXI)

were tested in plant feeding experiments with Vinca rosea and the work on all but (XXIX) is complete. Verbenalin (XXVII) and dihydroverbenalin (XXVIII) were labelled by tritium exchange and were found to be totally ineffective as precursors of the indole alkaloids. Similarly, monotropeine methyl ester (XXX), tritium labelled at the ester methyl gave zcro incorporation into the alkaloids. This result not only points strongly against the monotropeine system as the correct monoterpene but also shows, most<smiles>COC(=O)C1=COC(C)C2CN3CCc4c([nH]c5ccccc45)C3CC1C(C(C)=O)=COC(OC)C2C(C)=O</smiles><smiles>CCC1=CC2CN3CCc4c([nH]c5ccccc45)C1(C2)C3=O</smiles>
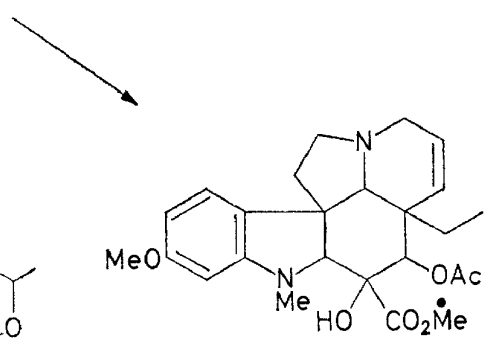

Figure 11 


\section{BIOSYNTHESIS OF THE INDOLE AND COLCHICUM ALKALOIDS}

importantly, that the labelled methyl group does not undergo transfer into the methylating system of the plant. Thus, when loganin (XXXI), also ${ }^{3} \mathrm{H}$-labelled at the methyl ester group afforded good incorporations of activity into all three types of indole alkaloid [ca. 1 per cent into vindoline (VII)] we felt confident that the explanation was not a trivial one of methyl transfer (Figure 11). This was put beyond doubt by converting the active vindoline first into desacetyl vindoline (VII, $\mathrm{OH}$ in place of OAc), without loss of activity, and then reducing desacetylvindoline to the diol (VIII). Less than $0 \cdot 1$ per cent of the original activity was retained in the diol proving<smiles>CC(C)=CCCC(C)=CCO</smiles>

Geraniol

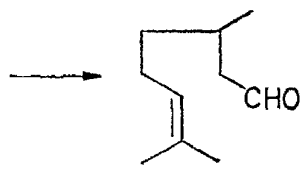

Citronellal

(XXXII)

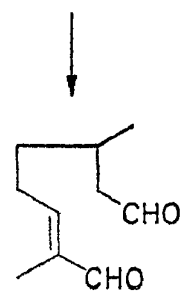

Iridodial

(XXXIII)<smiles>[R]CC1CC2C1CC(O)C1CC(C(C)=O)=COC(OCC)C12</smiles>

Loganin; $\mathrm{R}=\mathrm{H}$

Hydroxyloganin; $\mathrm{R}=\mathrm{OH}$

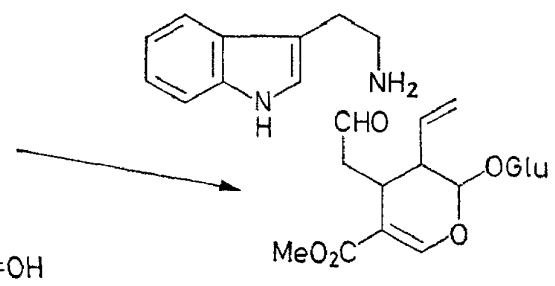<smiles>C=CC1CN2CCc3c([nH]c4ccccc34)C2CC1/C(=C\O)C(C)=O</smiles>

(XXXIV)

Figure 12 


\section{A. R. BATTERSBY}

that the ester methyl group carries all the activity and that none is present in the $>\mathrm{NMe}$ or aryl OMe groups; this result eliminates methyl transfer. Both ajmalicine and catharanthine (see Figure 11) were also highly radioactive and were proved to be labelled solely at their $O$-methyl groups. So the supreme importance of the cyclopentane monoterpene system for the biosynthesis of the indole alkaloids is established and loganin (XXXI) is identified as one of the key intermediates.

The pathway to the large and varied family of indole alkaloids can now take real form and Figure 12 shows an attractive sequencet. Some parts of the scheme rest on the firm experimental basis described so far in this lecture and the rest are under intensive study. Very recent experiments indicate that the conversion of the corynantheine-strychnine $\mathrm{C}_{9-10}$ unit into the Aspidosperma and Iboga $\mathrm{C}_{9-10}$ units occurs after introduction of the nitrogen but further work is necessary here; this is in progress.

The problem is at a most fascinating stage where the researcher can see that the precise detail of the pathway to the indole alkaloids cannot now escape him.

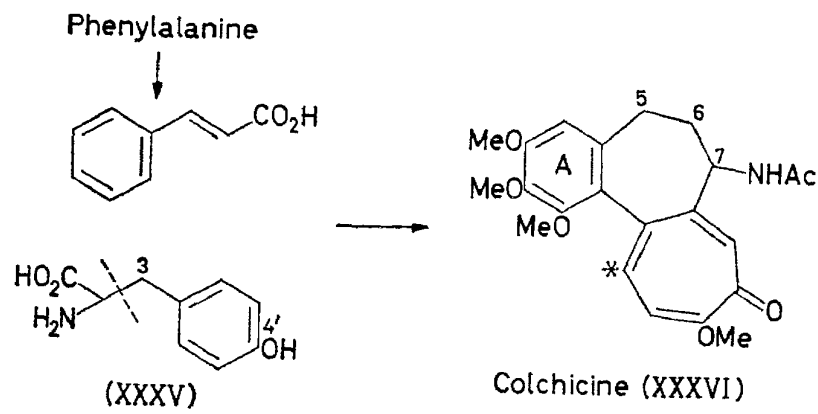

Figure 13

Let us now turn to the other problem, that posed by colchicine (XXXVI) and its relatives. One must determine the origin of the tropolone ring and also explain how the nitrogen atom comes to be placed in this unusual position; the solution here has proved to be a great surprise. The early tracer work established that ring $A$ of colchicine and the atoms 5, 6 and 7 are derived from phenylalanine by way of cinnamic acid by steps which were not understood at that stage $e^{43-45}$. We further found that when $\left[3-{ }^{14} \mathrm{C}\right]$ tyrosine was fed to Colchicum autumnale plants, it was incorporated well into colchicine to label the tropolone ring specifically at the starred position (Figure 13) and on this basis we put forward ${ }^{45,46}$ the biosynthetic scheme shown in Figure 14. Here the suggestion is that a $\mathrm{C}_{6}-\mathrm{C}_{3}$ residue from cinnamic acid is combined with a $\mathrm{C}_{6}-\mathrm{C}_{1}$ unit arising from tyrosine, to afford a $\mathrm{C}_{6}-\mathrm{C}_{3}-\mathrm{C}_{6}-\mathrm{C}_{1}$ system. Phenol oxidation ${ }^{5,6}$ could then generate the dienone

tWe must emphasize that several closely similar schemes could be written in which the sequence of operations is altered. For example, though at present it is at tractive to consider cleavage of the cyclopentane ring before the nitrogenous portion of the molecule is introduced, the evidence is indirect. Plausible schemes reversing the order can be written. Appropriate experiments are in hand. 


\section{BIOSYNTHESIS OF THE INDOLE AND COLCHICUM ALKALOIDS}

in which $\mathrm{X}$ is some good leaving group, possibly, we thought, a phosphate ester. Homoallylic assistance ${ }^{47}$ of the separation of $\mathrm{X}$ could then bring about ring expansion as illustrated ${ }^{46}$. The label from $\left[3-{ }^{14} \mathrm{C}\right]$ tyrosine would appear by this process at the correct position in the tropolone ring. This idea was supported by Leete ${ }^{48}$ who fed $\left[4^{\prime}-14 \mathrm{C}\right]$ tyrosine (see XXXV) to the plants; the isolated colchicine was labelled only at the carbonyl carbon of the tropolone ring. The $\mathrm{C}_{6}-\mathrm{C}_{3}-\mathrm{C}_{6}-\mathrm{C}_{1}$ "precursor" with $\mathrm{X}$ as $\mathrm{OH}$ (Figure 14) was in fact synthesized in labelled form at Liverpool and was fed to autumn crocus plants but there was no incorporation of activity; this is as it should be as will become clear in the sequel.

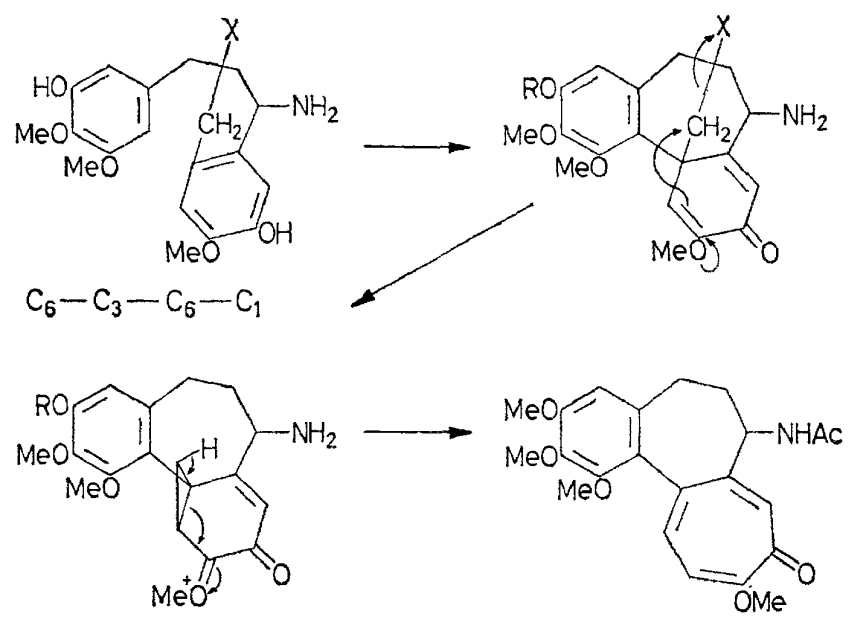

Figure 14

Here again the tracer studies were able to leap forward as a result of crucial information obtained in related structural studies. Androcymbium melanthioides is closely related to the autumn crocus and it contains several alkaloids ${ }^{49}$, among them colchicine and one of unknown structure named androcymbine. As for ipecoside, it is outside the scope of this lecture to describe how the structure and absolute stereochemistry (XXXVII, $\mathrm{R}=\mathrm{H}$ ) were determined $^{50}$ (in joint work with Professor F. Santavý). The key reaction was the reductive cleavage ${ }^{51}$ of $O$-methylandrocymbine (XXXVII, $\mathrm{R}=\mathrm{Me}$ ) to afford the 1-phenethylisoquinoline (XXXVIII) which was synthesized ${ }^{50}$. Not only was androcymbine of great interest by its being the first 1-phenethylisoquinoline alkaloid to be discovered, but also because of its relationship to dienone (XXXIX), the hypothetical "precursor" of colchicine. Moreover, the absolute stereochemistry of androcymbine is the same as that of colchicine. It was clear that all the available information would fall perfectly into place if colchicine is biosynthesized from a 1-phenethylisoquinoline precursor. On this basis, structure (XXXIX) derived directly from tracer experiments requires extension to that of $O$-methylandrocymbine (XXXVII, $\mathrm{R}=\mathrm{Me}$ ). The biosynthetic scheme shown in Figure 15 can now be considered for colchicine and for the base 
A. R. BATTERSBY
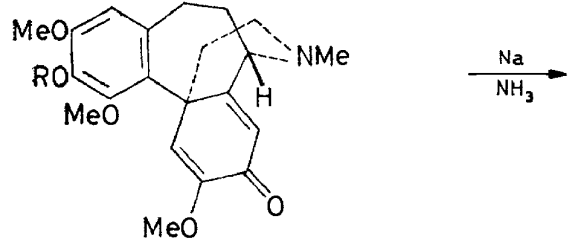

Androcymbine (XXXVII); $R=H$

[A. melanthioides]

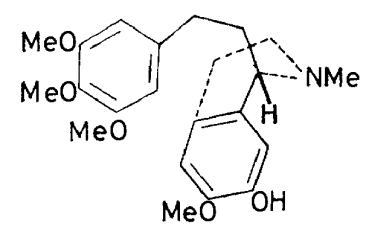

$(X X X V I I I)$

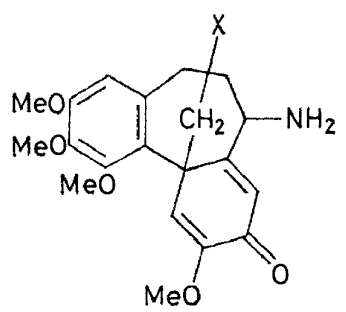

$(X X X I X)$

which also occurs in Colchicum species, demecolcine (XLVIII). The first few steps are best considered later and the present consideration can start at the diphenolic l-phenethylisoquinoline (XLIV). Phenol oxidation, methylation of the dienone to yield $O$-methylandrocymbine (XLV; $R=\mathrm{Me}$ ), and hydroxylation to form (XLVI; $\mathrm{X}=\mathrm{H}$ ) need no comment and the homoallylic assistance of ionization has been considered earlier. In this case, electron release from nitrogen can satisfy the deficiency on oxygen and models indicate that this process should be a favourable one. The resultant imine (XLVII) could then readily hydrolyse to afford demecolcine (XLVIII) which on this view precedes colchicine in the biosynthetic process.

Several crucial tests of this scheme can be made. Firstly, it collapses if $O$-methylandrocymbine $(\mathrm{XLV} ; \mathrm{R}=\mathrm{Me}$ ) is not a precursor of colchicine. In the experimental test, it was gratifying to find that this substance is incorporated without randomisation of the label into colchicine (Colchicum autumnale) with the high yield of over 15 per cent. Further, the isoquinoline (XLIV) was synthesized ${ }^{14} \mathrm{C}$-labelled at the indicated position and was used by the plants to make colchicine in over 10 per cent yield; degradation showed the colchicine to be labelled solely at the expected site. These two experiments laid open the problem of colchicine biosynthesis and we can now turn to researches which probed the detailed mechanism of this remarkable pathway. Much of this can be carried out by using the correctly labelled forms of the important 1-phenethylisoquinoline (XLIV), since a carbon-14 label at position 6 is now known to be retained and thus can act as an internal standard for the experiments which follow.

If the pathway outlined in Figure 15 is correct, then several strict requirements are imposed upon the incorporation of (XLIV) into colchicine and the twelve labels shown in Figure 16 are required to test these points. Of course, use of a dodecatuply labelled substance in plant feeding experiments 
BIOSYNTHESIS OF THE INDOLE AND COLCHICUM ALKALOIDS

Phenylalanine
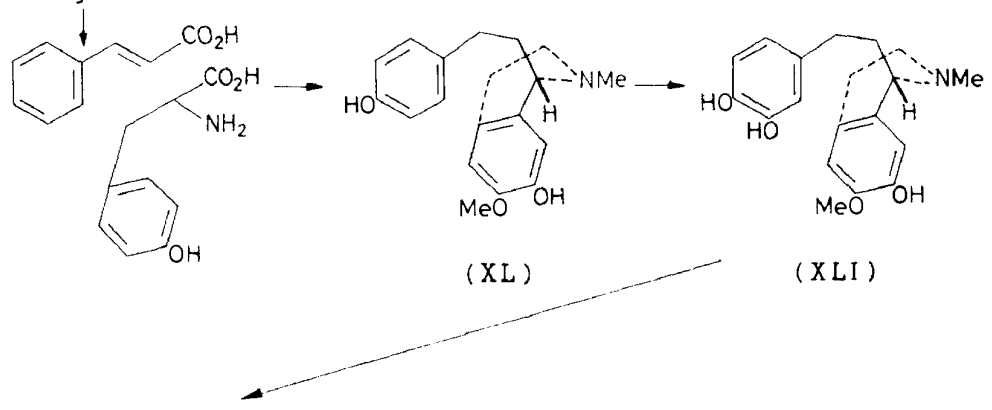

$(X L I)$
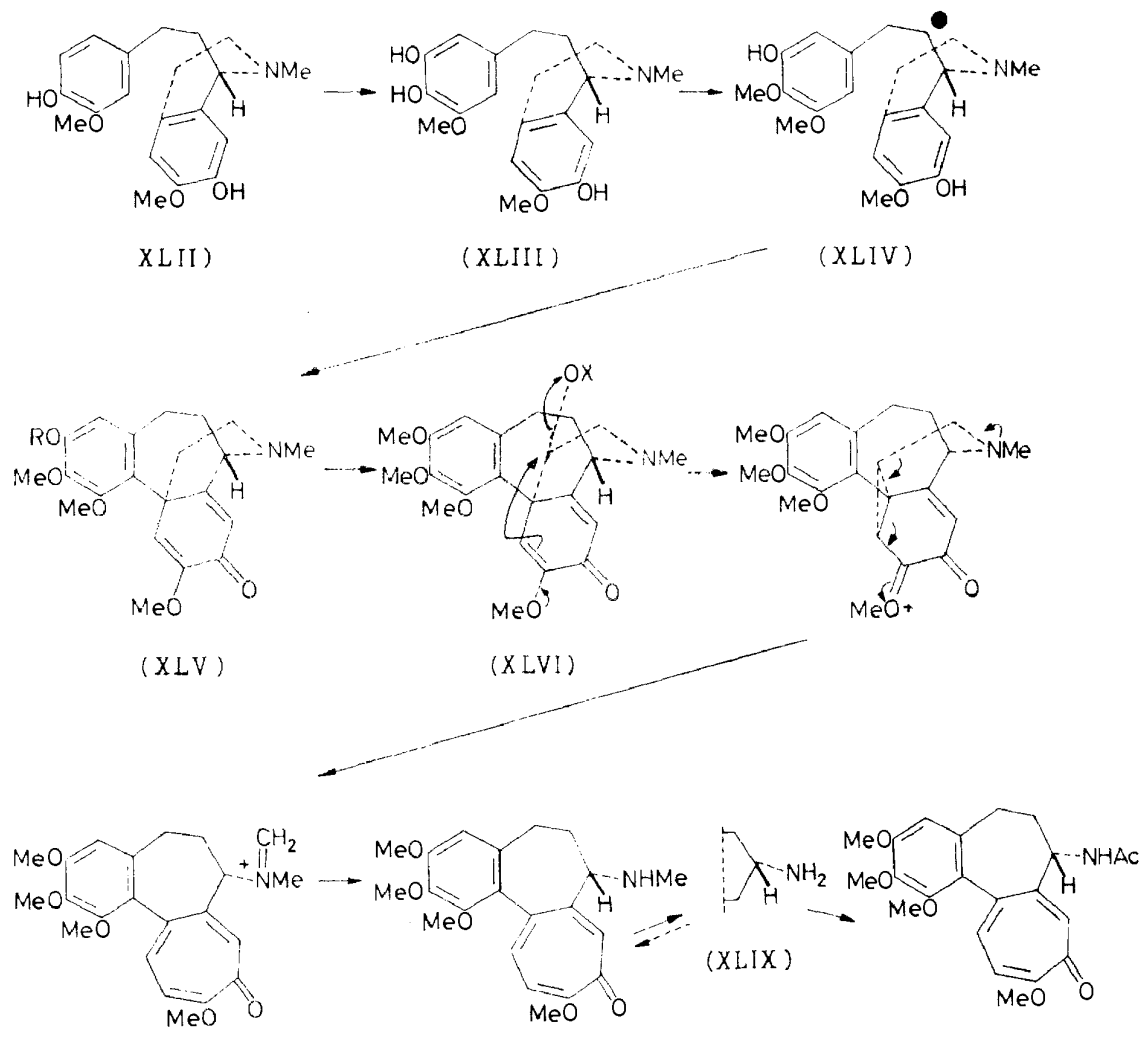

(XLVII)

Demicolcine (XLVIII)

Colchicine

Figure 15

would make the problem of degrading the isolated colchicine an extremely difficult one and therefore the twelve labels were grouped into convenient sets for separate administration to the plants. Several different syntheses of this precursor were required to allow labelling to be achieved at the various required points but it is not necessary here to cover this aspect. 


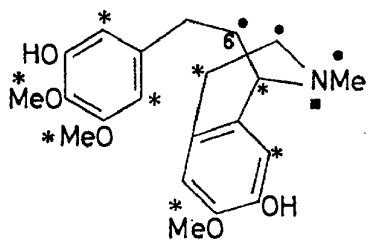

- Carbon-14

- Nitrogen-15

* Tritium

$(X L I X)$

Figure 16

The various requirements of the proposed biosynthetic pathway (Figure 15) can now be considered in turn together with the results gained so far from the multiply labelled precursor (XLIX). (a) The nitrogen atom must be retained. This is in sharp contrast to most of the earlier ideas on colchicine biosynthesis in which the nitrogen was thought to be introduced after the main skeleton had been constructed. The ${ }^{15} \mathrm{~N}:{ }^{14} \mathrm{C}$ experiment showed that the dilution of ${ }^{14} \mathrm{C}$ from precursor (XLIX) to colchicine was 157 and this matched perfectly the dilution of ${ }^{15} \mathrm{~N}$ which was 156 . The nitrogen atom of colchicine is thus proved to be that of the original isoquinoline. The ${ }^{15} \mathrm{~N}$ analysis was carried out at Saskatoon by Drs. E. W. Underhill and L. R. Wetter and we are most grateful to these Canadian colleagues. (b) One of the three ${ }^{3} \mathrm{H}$ atoms attached directly to the aromatic nuclei of (XLIX) should be lost and the ${ }^{3} \mathrm{H}:{ }^{14} \mathrm{C}$ ratio found in the isolated colchicine proved this to be precisely correct. (c) All three methoxyl groups should remain intact and here some simple degradations (Figure 17) of the colchicine were required to determine the necessary ${ }^{3} \mathrm{H}:{ }^{14} \mathrm{C}$ ratios. These established that no significant loss of any of the methoxyl groups occurs during the biosynthesis.

We can now turn to the mechanism of the ring expansion step. One would expect that direct enzymatic hydroxylation of $O$-methylandrocymbine (XLV, $\mathrm{R}=\mathrm{Me}$ ) to form the hydroxy derivative (XLVI, $\mathrm{X}=\mathrm{H}$ ), would be a stereospecific one and this should remove half the tritium present at this position in the labelled precursor (XLIX). Obviously if this carbon reaches the carbonyl state of oxidation, all the tritium will be lost whereas nonstereospecific oxidation will lead to a retention of some 85 per cent of the original tritium due to the ${ }^{3} \mathrm{H}$ isotope effect; this we know from other tracer experiments ${ }^{52}$. The loss of tritium found for colchicine biosynthesis was 56 per cent in clear agreement with a stereospecific hydroxylation reaction. Whether the difference from 50 per cent is significant is not yet known since this is near the limit of accuracy for the determination of ${ }^{3} \mathrm{H}:{ }^{14} \mathrm{C}$ ratios. The main point, however, is proved and an answer to this secondary one must wait the outcome of more refined experiments now in hand.

The mechanism requires that the bridge carbon atom adjacent to the nitrogen of (XLIX) must be cleaved off in the formation of colchicine and here the ratios in the multiply labelled experiment showed that $c a .85$ per cent had indeed been lost. This difference from the expected value (100 per cent) is greater than the experimental error of counting and it was necessary 


\section{BIOSYNTHESIS OF THE INDOLE AND COLCHICUM ALKALOIDS}

to show by conversion of the colchicine into trimethylcolchicinic acid (Figure 17) that no significant activity was present in the $N$-acetyl group. The results so far establish that the bridge carbon is completely lost in accord with the scheme but a little of the ${ }^{14} \mathrm{C}$ activity it carries is probably trapped in the plant's metabolic pools (particularly the one carbon and two carbon pools). A small part of the avitivity could be passed back in this way rather generally into the colchicine then being synthesized. This would account well for our findings.

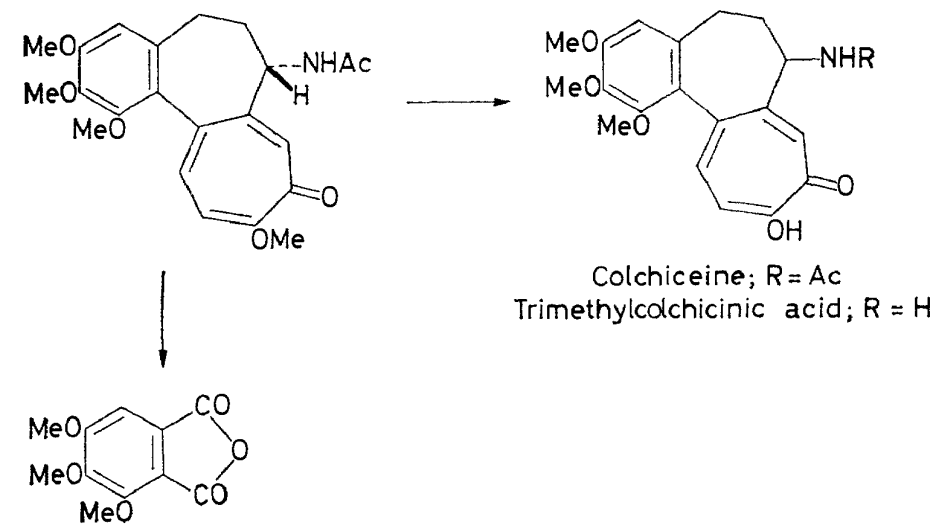

Figure 17

A similar explanation probably also holds for the values obtained when the plants were fed with (XLIX) labelled at the $N$-methyl group and carrying appropriate labels as internal standards. Here, the $N$-methyl group was fully retained during the biological conversion of (XLIX) into demecolcine (XLVIII) in accord with the scheme but for colchicine, the fall in ${ }^{14} \mathrm{C}$ activity corresponded to an elimination of $c a .90$ per cent of the $N$-methyl label. Since the $N$-acetyl group of colchicine was shown not to be significantly labelled in this experiment, a small general feed-back of activity is the most probable explanation. Of course, the extent of this feed-back can be determined experimentally, and this is in hand.

A study of the final steps of the biosynthetic scheme (Figure 15) provided valuable further evidence. $\left[O\right.$-methyl- $\left.{ }^{3} \mathrm{H}\right]$ Demecolcine (XLVIII) was converted into colchicine to the high extent of 14 per cent in Colchicum autumnale plants and there was only minor conversion of labelled colchicine into demecolcine, in this case using $C$. byzantinum. Further, a very satisfactory chemical method was devised for the preparation of desacetylcolchicine (XLIX) from colchicine which allowed the preparation of the labelled desacetyl base (XLIX). When this was administered to the plants, it was incorporated very well into colchicine (38 per cent) and also to a much smaller extent $(3.6$ per cent) into demecolcine. Clearly the forward path demecolcine $\rightarrow$ desacetylcolchicine $\rightarrow$ colchicine is the major one.

The researches which have been outlined define in considerable detail the pathway from the diphenolic base (XLIV) to demecolcine and colchicine. We can go further than this. The various 1 -phenethylisoquinolines $(\mathrm{XL})$, 


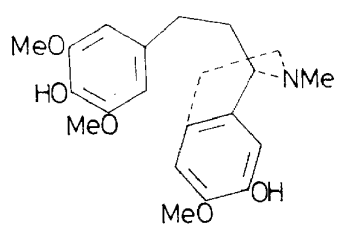

(L)

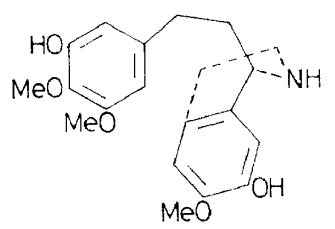

( III)

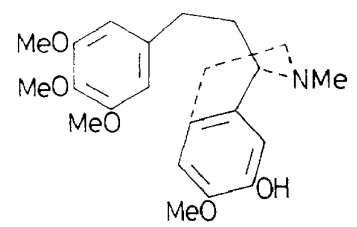

(LI)

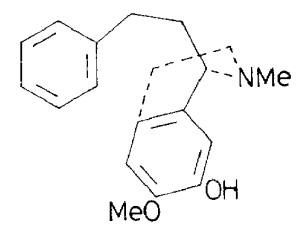

(L III)

(XLII), and (XLIII) have all been synthesized carrying skeletal ${ }^{14} \mathrm{C}$-labels and they are all incorporated into colchicine to extents entirely consistent with the illustrated sequential build up of oxygenation $\dagger$.

The pathway for colchicine and its relatives is thus known almost completely and it is a very surprising one. Colchicine now falls satisfyingly into place, rather than being an "odd man out" in the alkaloid field. Every organic chemist will admire the beauty of the natural pathway and a synthesis of colchicine by this sequence is a tempting possibility. The necessary experimental work is in progress.

The work I have described herein could only have been achieved by an enthusiastic and vigorous team effort and I cannot praise my colleagues too highly. Drs. R. T. Brown, B. Gregory, R. S. Kapil, J. A. Knight, J. A. Martin, and A. O. Plunkett carried out all the recent work on the indole and Ipecacuanha alkaloids. The group researching on colchicine and its relatives comprised $A$. Barker, J. H. Clements, $E$. McDonald, and Drs. R. B. Herbert and R. Ramage. In addition to his own work in the colchicine area, Dr. Ramage and my other senior colleague, Dr. J. Staunton, made innumerable contributions to the general good of the work.

Many friends helped us with rare alkaloids and terpenes and we are greatly indebted for such gifts to Drs. N. Neuss, H. T. Openshaw, G. F. Smith, and W.I. Taylor and to Professors G. Büchi, G.W.K. Cavill, C. Djerassi, H. Inouye, E. Ramstad, E. R. Ritchie, and F. Santaý. We record our warmest thanks to these colleagues.

†The bases (L), (LI), (LII), and (LIII) were also prepared in labelled form. In one way or another, these are the wrong "precursors" bearing in mind the reasoning outlined in this lecture. For example, (LI) and (LIII) lack phenolic groups in the correct positions to permit the phenol coupling step. All these substances failed to act as precursors of colchicine in the autumn crocus. 


\section{BIOSYNTHESIS OF THE INDOLE AND COLCHICUM ALKALOIDS}

\section{References}

1 Reviewed inter al by A. R. Battersby. Quart. Rev. 15, 259 (1961);

K. Mothes and H. R. Schütte. Angew Chem. 75, 265, 357, (1963).

2 R. Robinson. The Structural Relations of Natural Products, Clarendon Press, Oxford 1955, and earlier references cited therein.

3 C. Schöpf. Naturwiss. 39, 241 (1952), and earlier references cited therein.

${ }^{4}$ R. B. Woodward. Angew. Chem. 68, 13 (1956).

5 D. H. R. Barton and T. Cohen. Festschrift A. Stoll, Birkhauser, Basle, 1957, p.117.

${ }^{8}$ H. Erdtman and C. A. Wachtmeister. Festschrift A. Stoll, Birkhauser, Basle, 1957, p. 144.

${ }^{7}$ L. Wenkert and N. V. Bringi. J. Am. Chem. Soc. 81, 1474 (1959);

E. Wenkert. J. Am. Chem. Soc. 84, 98 (1962).

8 A. R. Battersby. Tilden Lecture, Proc. Chem. Soc. 189 (1963).

${ }^{9}$ D. H. R. Barton. Hugo Muller Lecture. Proc. Chem. Soc., 293 (1963).

10 The Alkaloids, Vol. VIII, Ed. R. H. F. Manske, Academic Press, New York (1965).

11 M. Hesse. Indolalkaloide in Tabellen Springer-Verlag, Berlin (1964).

12 E.g., E. Leete. Tetrahedron 14, 35 (1961).

13 E. Schlitter and W. I. Taylor. Experientia 16, 244 (1960).

14 R. B. Woodward. Nature 162, 155 (1948).

15 E. Leete, S. Ghosal, and P. W. Edwards, J. Am. Chem. Soc. 84, 1068 (1962).

16 A. R. Battersby. Biogenesi delle Sostanze Naturali, Accademia Nazionale dei Lincei, Roma, 1964, p. 57.

17 A. R. Battersby, R. Binks, W. Lawrie, G. V. Parry, and B. R. Webster. Proc. Chem. Soc. 369 (1963).

18 A. R. Battersby, R. Binks, W. Lawrie, G. V. Parry, and B. R. Webster. J. Chem. Soc. 7459 (1965).

${ }_{19} \mathrm{H}$. Goeggel and D. Arigoni. Experientia 21, 369 (1965).

20 D. H. R. Barton, G. W. Kirby, R. H. Prager, and E. M. Wilson. J. Chem. Soc. 3990 (1965).

${ }^{21}$ K. Stolle, D. Gröger, and K. Mothes. Chem. and Ind. 2065 (1965).

22 P. N. Edwards and E. Leete. Chem. and Ind. 1666 (1961);

E. Leete and S. Ghosal. Tetrahedron Letters, 1179 (1962).

${ }^{23}$ E. Leete, A. Ahmad, and I. Kompis, J. Am. Chem. Soc. 87, 4168 (1965).

${ }^{24}$ R. Thomas. Tetrahedron Letters 544 (1961).

¿5 A. R. Battersby, R. T. Brown, R. S. Kapil, A. O. Plunkett, and J. B. Taylor. Chem. Comm. 46 (1966).

${ }^{26}$ F. McCapra, T. Money, A. I. Scott, and I. G. Wright. Chem. Comm. 537 (1965).

${ }^{27} \mathrm{H}$. Goeggel and D. Arigoni. Chem. Comm. 538 (1965).

${ }^{28}$ J. v. Euw and T. Reichstein. Helv. Chim. Acta 47, 711 (1964).

${ }_{29}$ J. W. Cornforth, R. H. Cornforth, A. Pelter, M. G. Horning, and G. Popjak. Tetrahedron 5, 311 (1959).

${ }^{30}$ N. Neuss and M. Gorman. Tetrahedron Letters 206 (1961).

${ }^{31}$ G. F. Smith and M. A. Wahid. J. Chem. Soc. 4002 (1963).

${ }^{32}$ H. Conroy, P. R. Brook, M. K. Rout, and N. Silverman. J. Am. Chem. Soc. 80, 5178 (1958);

H. Conroy, P. R. Brook and Y. Amiel. Tetrahedron Letters No. 11, 4 (1959).

${ }^{33}$ D. A. Yeowell and H. Schmid. Experientia 20, 250 (1964).

${ }^{34}$ A. Mondon and G. Teege. Chem. Ber. 91, 1014 (1958).

35 A. R. Battersby, R. T. Brown, J. A. Knight, J. A. Martin and A. O. Plunkett. Chem. Comm. 346 (1966).

${ }^{36}$ P. Loew, H. Goeggel, and D. Arigoni. Chem. Comm. 347 (1966).

37 E. S. Hall, F. McCapra, T. Money, K. Fukumoto, J. R. Hanson, B. S. Mootoo, G. T. Phillips, and A. I. Scott. Chem. Comm. 348 (1966).

38 A. R. Battersby and B. J. T. Harper J. Chem. Soc. 1748 (1959).

${ }^{39}$ G. Büchi and R. E. Manning. Tetrahedron 181049 (1962).

${ }^{40}$ G. Djerassi, T. Nakano, A. N. James, L. H. Zalkow, E. J. Eisenbraun, and J. N. Shoolery. J. Org. Chem. 26, 1192 (1961).

${ }^{41}$ H. Inouye, T. Arai, and Y. Miyoshi. Chem. Pharm. Bull. Japan, 12, 888 (1964).

42 A. J. Birch and J. Grimshaw. J. Chem. Soc. 1407 (1961); K. Sheth, E. Ramstad, and J. Wolinsky. Tetrahedron Letters 394 (1961), and references therein. 


\section{A. R. BATTERSBY}

43 A. R. Battersby and J. J. Reynolds. Proc. Chem. Soc. 346 (1960).

44 E. Leete and P. E. Nemeth. J. Am. Chem. Soc. 82, 6055 (1960);

E. Leete. J. Am. Chem. Soc. 85, 3666 (1963).

${ }^{45}$ A. R. Battersby, R. Binks, J. J. Reynolds, and D. A. Yeowell. J. Chem. Soc. 4257 (1964).

${ }^{46}$ A. R. Battersby, R. Binks, and D. A. Yeowell. Proc. Chem. Soc. 86 (1964);

A. R. Battersby and R. B. Herbert. Proc. Chem. Soc. 260 (1964).

${ }^{47}$ cf. O. L. Chapman and P. Fitton. J. Am. Chem. Soc. 85, 41 (1963).

${ }^{48}$ E. Leete. Tetrahedron Letters 333 (1965).

49 J. Hrbek, jun., and F. Santavý. Coll. Czech. Chem. Comm., 27, 255 (1962).

${ }^{50}$ A. R. Battersby, R. B. Herbert, L. Pijewska, and F. Santavý, Chem. Comm. 228 (1965).

${ }^{51}$ M. P. Cava, K. Nomura, R. H. Schlessinger, K. T. Buch, B. Douglas, R. F. Rattauf, and J. A. Weisbach. Chem. and Ind. 222 (1964).

${ }^{52}$ A. R. Battersby, M. Hirst, and J. Staunton. Unpublished work. 